\title{
Polymorphism study of MTHFR 677C $\rightarrow$ T and its correlation with oxidative stress and their influence on female infertility in Erbil - Iraq
}

\author{
Muthanna A. Thabit* \\ Khalid F. AL-Rawi1* \\ *Department of Chemistry, College of Science, University of Anbar, Al-Anbar, Iraq. \\ ** Medical research center, Hawler Medical University, Erbil, Iraq.
}

E-mail: Muthna89ba@yahoo.com

Received 8/3/2017

Accepted 27/4/2017

(c) (1)

This work is licensed under a Creative Commons Attribution 4.0 International License.

\begin{abstract}
:
This research includes a study of Methylenetetrahydrofolate reductase gene's allele $677 \mathrm{C} \rightarrow \mathrm{T}$ and its correlation with oxidative stress and their impact on female infertility. Fifty infertile women with the range age (23-42) years and twenty five fertile women with the range age (22-39) years as control group living in Erbil city were selected. The serum level of Malondialdehyde (MDA), superoxide dismutase (SOD), prolactin hormone (PRL), Luteinizing hormone (LH), Thyroid stimulating hormone (TSH), Triiodothyronine hormone $\left(\mathrm{T}_{3}\right)$, and Thyroxine hormone $\left(\mathrm{T}_{4}\right)$ were measured, also a body mass index (BMI) was calculated. A restriction enzyme (Hinf1) was used to improve the mutation in DNA bands of infertile women. The results showed significant increases in MDA level, SOD activity, BMI, PRL, LH, $\mathrm{TSH}$, and $\mathrm{T}_{4}$ in patients women compared with the control group. The results show non-significant differences in $\mathrm{T}_{3}$ hormone levels. The results also show a mutation in DNA bands of infertile women compared with fertile control group.
\end{abstract}

Key words: Female infertility (FI), Methylenetetrahydrofolate reductase (MTHFR) gene, Oxidative stress (OS).

\section{Introduction:}

Infertility is the most important clinical problem, affecting people around the world psychosocially and physically, Infertility is a disease of the reproductive system defined by the failure to achieve a clinical pregnancy after 12 months of regular intercourse without contraception [1]. Infertility can be divided into two major types: primary infertility which characterizes women who have never been able to conceive a pregnancy and secondary infertility which describes those who had at least one successful pregnancy but have not been able to obtain another [2]. Causes of female infertility (FI) include Endometriosis, Polycystic ovary syndrome (PCOS), Ovulatory disorders, tubal factors, age factor, body weight and obesity, and lifestyle factors [3]. 
Oxidative stress (OS) is caused by an imbalance between pro-oxidants and antioxidants, excessive amounts of reactive oxygen species (ROS) generation, nevertheless, may curb the body's characteristic antioxidant protection system, making an environment inappropriate for typical female physiological reactions. This can be promote to a numerous of reproductive ailments comprising endometriosis, PCOS, tubal illnesses, spontaneous abortion and unexplained infertility [4]. The role of ROS and FI has been a subject of large interest and research over the last decade. Antioxidants and ROS seem to have a physiological role in reproductive processes, including, fertilization, oocyte maturation, luteal regression, and endometrial shedding. Macrophages, neutrophils and granulosa cells in Graafian follicles are a source of ROS that are balanced by antioxidants [5]. OS has been recommended to be causal in etiologies such as endometriosis, tubal, peritoneal and unexplained infertility and even PCOS. The irregularities in the tubal peritoneal or endometrial environment which result in infertility are moderated by the generation of excessive pro-oxidants as obvious by elevate levels of ROS from the fluid evaluation, higher concentrations of ROS in these environments may have harmful effects on the spermatozoa, oocytes, sperm-oocyte interaction and embryos, both in the Fallopian tube and the peritoneal cavity, recent studies observing an increase in DNA damage in the leukocytes cells from women with PCOS. There was also an increased capability to OS induced damage in these women with PCOS, OS as is being implicated in the pathogenesis of PCOS may possibly explain the link with longterm complications of PCOS containing cardiovascular disease and malignancy [6]. Methylenetetrahydrofolate Reductase (MTHFR) is a protein-coding gene; it has a role in both folate and homocysteine metabolisms by catalyzing the conversion of 5,10methylenetetrahydrofolate to 5methylenetetrahydrofolate, using Flavin adenine dinucleotide (FAD) as a cofactor and regulating the metabolism of folate that affects DNA synthesis and methylation [7]. There are two common alleles of MTHFR gene, $677 \mathrm{C} \rightarrow \mathrm{T}$ and $1298 \mathrm{~A} \rightarrow \mathrm{C}$, which led to amino acid substitutions, $677 \mathrm{C} \rightarrow \mathrm{T}$ allele is present in either heterozygous $\mathrm{CT}$ in about $40 \%$ or homozygous TT in about $5-15 \%$ carrier state of individuals. Many studies showed that this allele may cause DNA hypo methylation that has been related to metabolic syndrome (MetS) and its components [8]. Methylation of DNA includes a covalent modulation of DNA and has been found to affect a diversity process which influences DNA function and integrity; furthermore, methylation of DNA has a critical role in the domination of gene activity [9].

\section{Patients and Methods:}

A total number of 50 samples of infertile women (primary infertility) with the range age (23-42) years, that already diagnosed with female infertility by the doctors in Maternity teaching hospital for fertility and I.V.F center in Erbil governorate-Iraq, and 25 samples of fertile women with the range age (22-39) years, as a control group. The period of the work took about six months (from April to October) 2016, with all required information's from both infertile and fertile women. Up to (4-5 ml) of blood was drawn and collected and divided into pre-labelled two groups of tubes, up to $1 \mathrm{ml}$ of blood collected in K3-EDTA tubes for DNA extraction and stored at refrigerator, and up to 3-4 $\mathrm{ml}$ collected in clot activator and gel tubes for blood serum, the blood samples were cooled on ice until the end of the experiment. Blood separation process was achieved by taking the 
clotting blood samples and then centrifuged at $4000 \mathrm{rpm}$ for 5-6 min. Then the blood serum was collected and stored at deep freezing $\left(-8--20^{\circ} \mathrm{C}\right)$ for later tests.

Laboratory Measurements:

Estimating the activity of superoxide dismutase (SOD) enzyme:

The method depends on the ability of SOD to inhibit the autoxidation of epinephrine to adrenochrome, the reaction occurs at $30^{\circ} \mathrm{C}, \mathrm{pH}=10.2$, and SOD measured at wavelength $480 \mathrm{~nm}$, absorbance was measured using Spectrophotometer (G10S UV-VIS, Thermo scientific, USA) [10].

Estimate of serum Lipid peroxide (Malondialdehyde (MDA)) levels:

Thiobarbituric acid (TBA) reacts with MDA, which is the final product of lipid peroxidation process, at $100{ }^{\circ} \mathrm{C}$ and acidic medium, to produce a pinkish complex product. The product is measured at $532 \mathrm{~nm}$, absorbance was measured using Spectrophotometer (G10S UV-VIS, Thermo scientific, USA) [11].

\section{Hormones measurements:}

The hormones levels of Triiodothyronine hormone $\left(\mathrm{T}_{3}\right)$, Thyroxine hormone $\left(\mathrm{T}_{4}\right)$, Luteinizing hormone (LH), Thyroid stimulating hormone (TSH), and prolactin were measured by (immulite xpi 2000) analyzer.

\section{Genomic DNA extraction:}

DNA was extracted from the blood samples using a method described by Geneaid Biotech Ltd., [12].

Estimate the Genomic DNA concentration and purity:

All the extracted DNA samples were tested by Thermo scientific Nanodrop 1000 spectrophotometer.

\section{Amplification experiment:}

All DNA samples were amplified by PCR technique, using a master premixture kit, manufactured by Bioneer corp. [13]. Specific oligonucleotide primers are used for MTHFR $677 \mathrm{C} \rightarrow \mathrm{T}$ gene, the sequence of the Forward primer is 5- CGA AGC AGG GAG CTT TGA GGC TG-3 $\square$ and Revers primer 5AGG ACG GTG CGGTGA GAG TG-3. Amplification was run in an automated thermocycler (Cg1-96, Corbett research, Australia). The mixture was initially denatured at $94{ }^{\circ} \mathrm{C}$ for 5 minutes, followed by (35) cycles for 30 seconds at $94{ }^{\circ} \mathrm{C}, 30$ seconds at $67{ }^{\circ} \mathrm{C}, 60$ seconds at $72{ }^{\circ} \mathrm{C}$, and 10 minutes for a final extension at $72{ }^{\circ} \mathrm{C}$. PCR products were run on $2 \%$ agarose gels (Promega, USA) and stained with $1 \mu \mathrm{g} / \mathrm{ml}$ ethidium bromide. The amplified 233 bp PCR products were digested with (Hinf1) (Roche, Germany) restriction enzyme, according to the manufacturer's instructions. The digested PCR products were separated on 3\% agarose gels and visualized with ethidium bromide staining using the gel documentation system (2500 Proxima, ISO Gen, Netherlands) [14].

\section{Body Mass Index (BMI):}

BMI was calculated, by measuring both weight and height of the body. The values were calculated as $\left(\mathrm{Kg} / \mathrm{m}^{2}\right)$.

\section{Results:}

Table (1) shows the results of MDA, SOD, and BMI for patients and controls. It shows a significant increase in MDA levels of patients $(0.03558 \pm 0.02012$ $\mu \mathrm{mol} / \mathrm{l})$ compared to controls $(0.006 \pm$ $0.00285 \mu \mathrm{mol} / \mathrm{l})$, at a probability $(\mathrm{P} \leq$ $0.05)$, respectively. It also shows showed a significant increase in SOD values of patients $(0.601 \pm 0.052$ $\mu \mathrm{mol} / \mathrm{min} / \mathrm{ml}$ ) compared to controls $(0.924 \pm 0.066 \mu \mu \mathrm{mol} / \mathrm{min} / \mathrm{ml})$ respectively. It also shows a significant increase in BMI values of patients $\left(27.128 \pm 2.99 \mathrm{~kg} / \mathrm{m}^{2}\right)$ compared to controls $\left(23.904 \pm 1.91 \mathrm{~kg} / \mathrm{m}^{2}\right)$ at probability $(\mathrm{P} \leq 0.05)$, respectively. 
Table (1): ): Means, SD \pm of MDA, SOD, and BMI, for patients and control groups.

\begin{tabular}{|c|c|c|c|c|}
\hline \multirow{2}{*}{ Variants } & \multicolumn{2}{|c|}{ Mean \pm SD } & \multirow{2}{*}{ T-test } & \multirow{2}{*}{ P $\leq \mathbf{0 . 0 5}$} \\
\cline { 2 - 3 } & Patients $\mathbf{N}=\mathbf{5 0}$ & Controls $\mathbf{N}=\mathbf{2 5}$ & & 0.0001 \\
\hline MDA $\boldsymbol{\mu m o l} / \mathbf{L}$ & $0.03558 \pm 0.02012$ & $0.006 \pm 0.003$ & 7.29 & 0.0001 \\
\hline SOD $\boldsymbol{\mu m o l} / \mathbf{m i n} / \mathbf{m l}$ & $0.924 \pm 0.066$ & $0.601 \pm 0.052$ & 8.84 & 0.0001 \\
\hline BMI $\mathbf{~ k g} / \mathbf{m}^{\mathbf{2}}$ & $27.128 \pm 2.99$ & $23.9 \pm 1.91$ & 4.8921 & 0.0001 \\
\hline
\end{tabular}

Table (2) shows the results of the hormones levels of (PRL, LH, TSH, $\mathrm{T}_{4}$ and $\mathrm{T}_{3}$ ) for patients and control groups. It shows a significant increase in PRL hormone levels of patients $(34.2088 \pm$ $14.92 \mathrm{ng} / \mathrm{ml}$ ) compared to controls $(10.3516 \pm 5.94 \mathrm{ng} / \mathrm{ml})$ respectively, and likewise presented a significant increase in LH hormone levels for patients (14.33 $\pm 1.8 \mathrm{ml} \mathrm{u} / \mathrm{ml}$ ) compared to controls $(7.912 \pm 2.32 \mathrm{ml} \mathrm{u} / \mathrm{ml})$, and the results indicate a significant increase in TSH hormone levels of patients $(7.69 \pm 1.55$ $\mu \mathrm{IU} / \mathrm{ml})$ compared to controls $(3.5968 \pm$ $1.63 \mu \mathrm{IU} / \mathrm{ml})$, and the results show a significant increase in $\mathrm{T}_{4}$ hormone levels of patients $(164.74 \pm 20.27 \mathrm{nmol} / \mathrm{l})$ compared to controls $(108.69 \pm 28.83 \mathrm{n}$ $\mathrm{mol} / \mathrm{l}$ ) respectively, for $\mathrm{T}_{3}$ hormone the results showed non-significant change in the hormone levels of patients $(3.32 \pm$ $0.72 \mathrm{nmol} / \mathrm{l})$ compared to controls $(3.12$ $\pm 0.58 \mathrm{n} \mathrm{mol} / \mathrm{l})$ respectively.

Table (2): Mean, $\mathrm{SD} \pm$ hormone levels, for patients and control groups.

\begin{tabular}{|c|c|c|c|c|}
\hline \multirow{2}{*}{ Hormones } & \multicolumn{2}{|c|}{ Mean $\mathbf{S D}$} & \multirow{2}{*}{ t-test } & \multirow{2}{*}{ P $\leq \mathbf{0 . 0 5}$} \\
\cline { 2 - 5 } & Patients $\mathbf{N}=\mathbf{5 0}$ & Controls $\mathbf{N = 2 5}$ & 7.68 & 0.0001 \\
\hline $\mathbf{L H} \mathbf{n g} / \mathbf{m l}$ & $34.2088 \pm 14.92$ & $10.3516 \pm 5.94$ & 13.2 & 0.0001 \\
\hline $\mathbf{T S H} \mathbf{\mu I U} / \mathbf{m l}$ & $14.33 \pm 1.8$ & $7.912 \pm 2.32$ & 10.58 & 0.0001 \\
\hline $\mathbf{T}_{\mathbf{4}} \mathbf{n ~} \mathbf{~ m o l} / \mathbf{L}$ & $7.69 \pm 1.55$ & $3.5968 \pm 1.63$ & 9.76 & 0.0001 \\
\hline $\mathbf{T}_{\mathbf{3}} \mathbf{n ~} \mathbf{~ m o l} / \mathbf{L}$ & $164.74 \pm 20.27$ & $108.69 \pm 28.83$ & 1.664 & 0.94873 \\
\hline
\end{tabular}

Figure (1) shows three bands at (233bp, $176 \mathrm{bp}$ and 57bp) in the DNA of patients women, while control group have only one single band at (233bp) in there DNA Figure (2). The results show significant differences in genotype distribution in patients women compared to healthy women as controls.

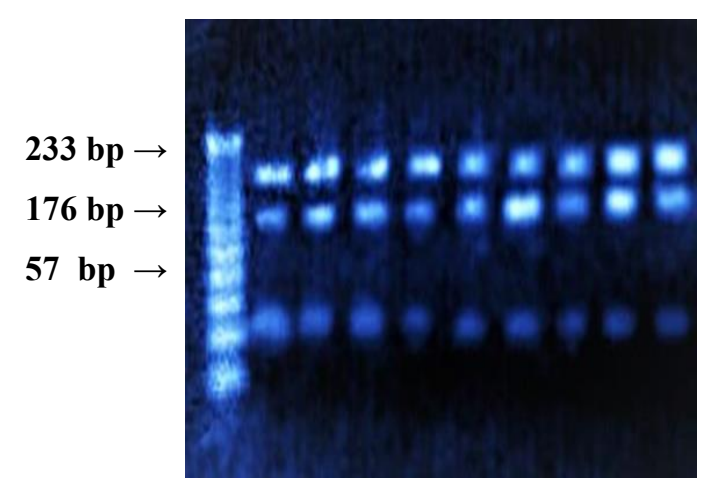

Fig. (1): Three bands in the DNA of infertile women in allele $\mathrm{C} / \mathrm{T}$ polymorphism, indicate a mutation in the MTHFR gene after digested with
(Hinf1) restriction enzyme using gel electrophoresis technique.

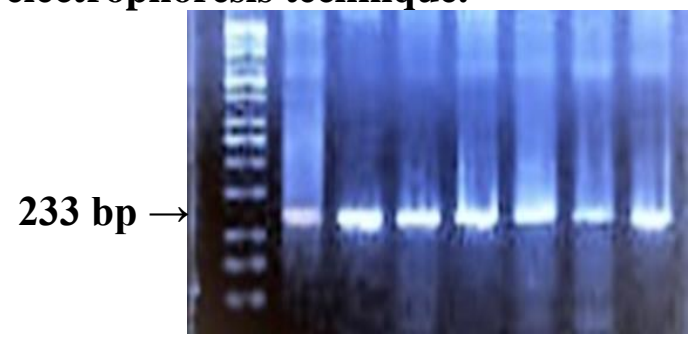

Fig. (2): One band in the DNA of fertile women with no mutation in the MTHFR gene using gel electrophoresis technique.

\section{Discussion:}

In this study a significant increase in MDA levels was observed in infertile women; this elevation in MDA levels is due to the increased generation of ROS due to the excess in oxidative damage generated in these patients. In turn, these oxygen species can oxidize various other important biomolecules including 
membrane lipids. This increase in MDA levels is in agreement with a study that reported an increase in MDA levels in patients with FI and especially patients with PCOS [15].

An increase in SOD activity levels may be due to excessive amounts of ROS that were generated through oxidative stress (OS), also the increase in SOD activity levels could be due to the response of the increase in OS in women patients with PCOS, dismutation of superoxide results in the development of $\left(\mathrm{H}_{2} \mathrm{O}_{2}\right)$. This lead to altering purines and pyrimidines and cause strand breaks in DNA resulting in DNA damage which may lead to gene mutation. A study indicated that the levels of SOD activity were observed to be higher in blood serum of women patients with PCOS [16].

The increase in BMI values in infertile women may be explained by obesity could intervene with ovarian functions and neuroendocrine that affect oocyte quality and thereby embryo development, implantation, and pregnancy outcome; however, the obesity decreasing both of fertility and ovulatory averages in healthy women [17].

The increased levels of PRL in infertile women is due to OS and ROS, which led to infertility due to a delay in the development of endometriosis. The increase in PRL levels could lead to dysfunction of the luteal phase, lack of ovulation and menopause, because of the inhibitation effect of PRL on the secretion of GnRH hormone. Many factors could lead to an increase in PRL levels such as cardiovascular diseases, pituitary gland tumors and hypothyroidism [18]. The increase in LH hormone levels possibly indicates that the infertile women could have PCOS and this led to irregularities in menstrual which leads to female infertility (FI) or a dysfunction occurs in the pituitary gland [19]. The increase in serum TSH hormone levels in infertile women could be due to thyroid gland dysfunction or to its diseases such as hypothyroidism which is commonly associated with menstrual irregularities, acute hypothyroidism also led to ovulatory dysfunction and this may be due to many interactions of thyroid hormones with the female reproductive system [20]. In this study the increased in $\mathrm{T}_{4}$ hormone levels in infertile women may be due to thyroid gland diseases such as hyperthyroidism, hypothyroidism and thyroid gland disorders; hence, reproductive and infertility are connected to defects in the endocrine, immune system or both. These systems are also directly related to the thyroid gland since the most thyroid autoimmunity common causes are hypothyroidism in women of reproductive age, the majority of women with thyroid dysfunction incidence menstrual irregularities, increased pregnancy miscarriage and infertility [21].

In this study, the results show that all the patient women had the three bands, one at $233 \mathrm{bp}$ and the two other were on $176 \mathrm{bp}$ and $57 \mathrm{bp}$ after digested by restriction enzyme (Hinf1), which means that all genotypes were heterozygote (CT) and one of the parents had the mutant gene (T), (Fig.1), while in the controls women (Fig. 2), all the samples were located at $233 \mathrm{bp}$ which means that all had wild type (CC) which won't be cut with restriction enzyme. The results in this study are in agreement with a study indicated a gene mutation in alleles $\mathrm{C} / \mathrm{T}$ polymorphism [22]. MTHFR $677 \mathrm{C} \rightarrow \mathrm{T}$ polymorphism was significantly associated with OS which; in turn, leads to FI, OS that can make DNA damage and folate deficiency. This could make a disorder in the structure of DNA. The allele $\mathrm{C} / \mathrm{T}$ was observed in patients women; furthermore, this study indicates that 
MTHFR gene plays a major role in FI [23].

\section{Conclusion:}

Oxidative stress is linked to female infertility due to its influence on many causes that lead to female infertility such as PCOS and endometriosis and raised the risk of female infertility. The results show a significant effect of oxidative stress, especially reactive oxygen species on MTHFR gene and exclusively C677T allele, which result in a mutation in the gene in women patients with female infertility.

\section{References}

[1] Michael, S. B.; Romeo, M. and Lulia, A. 2016. Female Infertility and Emerging Organic Pollutants of Concern. Curr Epidemiol Rep, 3:3950.

[2] Jorge, M. A.; and Mindy, S. M. 2011. Motherhood and Female Labor Supply in the Developing World: Evidence from Infertility Shocks. Journal of Human Resources, 46 (4) :800-826.

[3] Bari, M.; Battista, N.; Pirazzi, V.; and Maccarrone, M. 2011. The manifold actions of endocannabinoids on female and male reproductive events. Front Bio Sci. 16:498-516.

[4] Al-Gubory, KH.; Fowler, PA.; and Garrel, C. 2010. The roles of cellular reactive oxygen species, oxidative stress and antioxidants in pregnancy outcomes. Int. J Bio chem. Cell Biol. 42:1634-1650.

[5] Ashok, A.; Anamar, A., Beena, J. P.; Amani, S. and Sajal G. 2012. The effects of oxidative stress on female reproduction: a review. Reproductive Biology and Endocrinology. 10:49.

[6] Dinger, Y.; Akcay, T.; Erdem, T.; Ilker, E. and Gundogdu, D. 2005. DNA damage, DNA susceptibility to oxidation and glutathione level in women with polycystic ovary syndrome. Scand. J Clin. Lab Invest. 65: 721-728.

[7] Trimmer, E.E. 2013. Methylenetetrahydrofolate reductase: biochemical characterization and medical significance. Curr Pharm Des. 19 (14): 2574-93.

[8] Weiner, A. S.; Boyarskikh, U.A.; Voronina, E. N.; Mishukova, O.V. and Filipenko, M.L. 2014. Methylenetetrahydrofolate reductase C677T and methionine synthase A2756G polymorphisms influence on leukocyte genomic DNA methylation level. Gene, I: 168-172.

[9] Yannick, D.; Pierre, C.; William, C.; Cho, C. and Jerome, T. 2013. DNA methylation and cancer diagnosis. Int. J. Mol. Sci. 14: 15029-15058.

[10] Hara, P.; and Irwin, F. 1971. The role of superoxide anion in the autoxidation of Epinephrine and a simple assay for superoxide dismutase. Jbc, 247 (10):3170-3175.

[11] Kunio, y. 1982. Lipid Peroxides in Biology and Medicine. Institute of Biochemistry, Faculty of Medicine, university of Nagoya, Nagoya, Japan, pp. 220-230.

[12] Vogelstein, B. and Gillespie, D. 1979. Proc. Natl. Acad. Sci. USA 76.

[13] Wang, Y. 2006. The association between the MTHFR C677T and SHMT1 C1420T SNPs, the aberrant methylation of the MAGE A1 and CAGE gene and the carcinogenesis and development of ESCC. PhD., Hebei Medical University.

[14] Huang, G.; Wang, S.; SU, M.; Wang, T.; Cai, H.; Yin, H. and Sun G. 2013. Serum Folate, MTHFR C677T Polymorphism and Esophageal Squamous Cell Carcinoma Risk. Biomed Environ Sci., 26(12): 1008-1012.

[15] Mora, M.; Manuel, L.; María, I.; Miriam, O. and Hector F. 2013. Circulating markers of oxidative stress and polycystic ovary syndrome (PCOS): a systematic review and 
meta-analysis. Hum Reprod, 19 (3): 268-288.

[16] Volkan, T.; Ebru, D.; Burak, Z. and Fatih, S. 2014. Infertility and the presence of insulin resistance are associated with increased oxidative stress in young, non-obese Turkish women with polycystic ovary syndrome. jpag. (14): 1027-1034.

[17] Anjall, S.; Sathya, B.; Shalu, G. and Thankam, V. 2011. Effect of body mass index on in vitro fertilization outcomes in women. J. Of Human Reproductive Sciences, 3 (3): 135138.

[18] Amir, H.; Hossein, M. and Anoosh N. 2016. Comparison of the Levels of $\mathrm{LH}$ and FSH, TSH, Prolactin, Progesterone and Estradiol Hormones between Iranian Infertile Women with Polycystic Ovary Syndrome and Healthy Women. IJMRHS, 5 (12): 370-375.

[19] Yadav, A.; Arora, M.; Saini, V. and Jain, A. 2014. Serum gonadotropin and prolactin levels in females with primary infertility and thyroid dysfunction in North Indian population. JIRB. 2 (3): 88-91.

[20] Takehiro, H.; Osamu, W.; Yasushi, H. and Kaori, K. 2016. The impact of elevated thyroid stimulating hormone on female subfertility. Reprod Med biol 15:121-126.

[21] Poppe, K.; Velkeniers, B. and Glinoer, D. 2008. The role of thyroid autoimmunity in fertility and pregnancy. Nature. 4: 394-405.

[22] Majida, G. 2015. Study of Thyroid and Reproductive hormones levels in fertile and infertile women. J. ThiQar Sci. 5 (2): 31-35.

[23] Yves, J.R.; Erica, S.; Brian, D. and Kay, E. 2016. Oxidative stress and alterations in DNA methylation: two sides of the same coin in reproduction. Elsevier. 33 (6): 668683. 


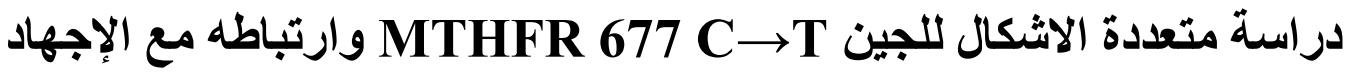 التأكسدي وتأثيرهما على العقم عند النساء في محافظة أربيل - العراق الإجن}

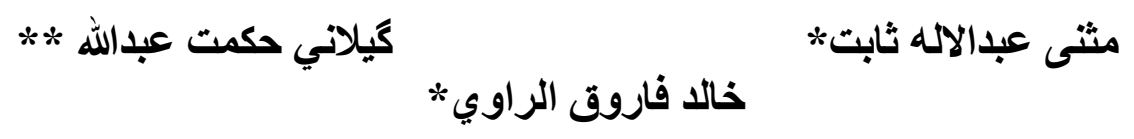

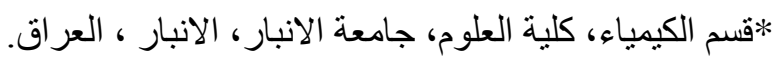

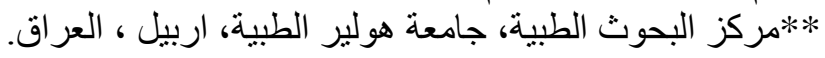

\section{البريد الاكتروني: Muthna89ba@yahoo.com}

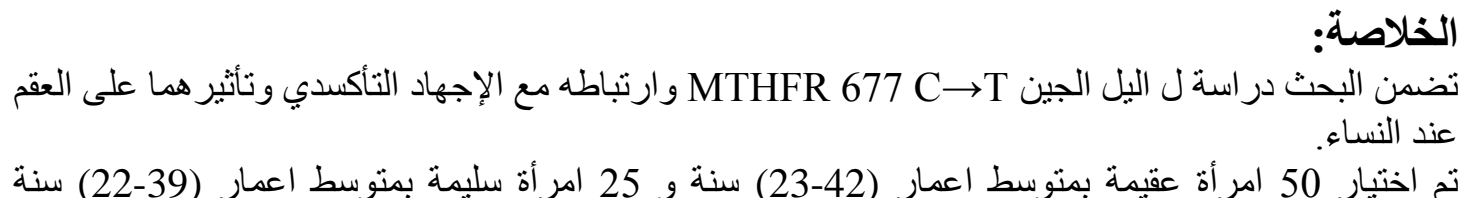

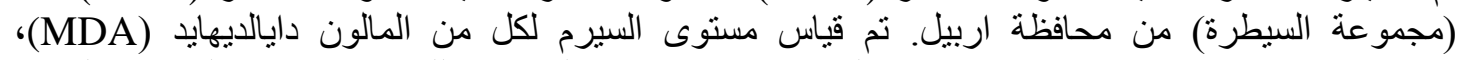

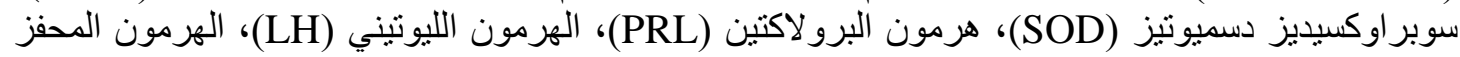

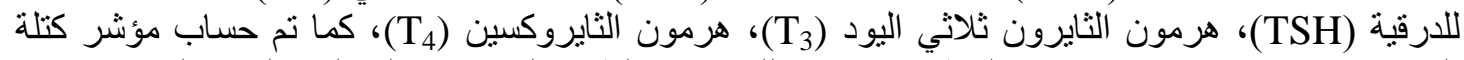

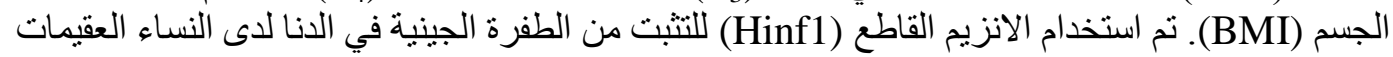

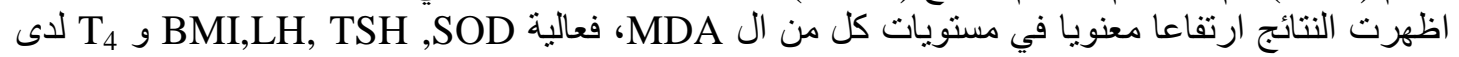

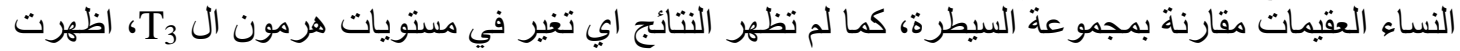

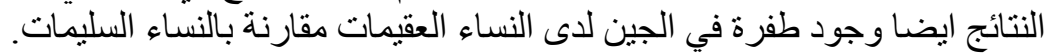

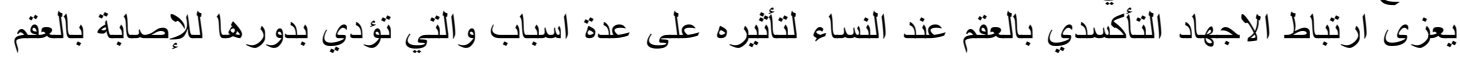

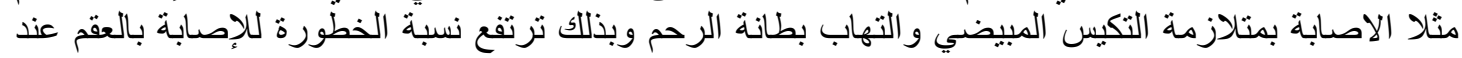

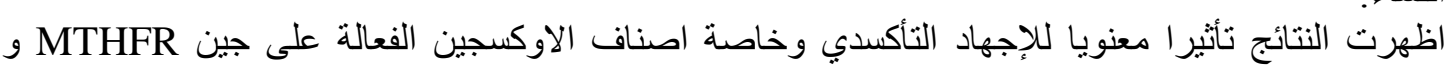

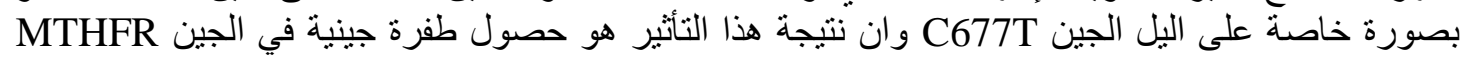

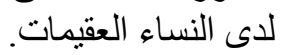

الكلمات المفتاحية : العقم عند النساء، جين ميثلين تيتر اهايدروفوليت ريدوكتيز ، الأجهاد التأكسدي. 